\title{
A INSERÇÃO DAS MULHERES NA POLÍTICA BRASILEIRA E A INTERPRETAÇÃO DAS NECESSIDADES: UMA ANÁLISE À LUZ DOS PRESSUPOSTOS TEÓRICOS DE NANCY FRASER
}

\author{
THE INSERTION OF WOMEN IN BRAZILIAN POLITICS AND THE \\ INTERPRETATION OF NEEDS: AN ANALYSIS IN THE LIGHT OF NANCY \\ FRASER'S THEORETICAL ASSUMPTIONS
}

\author{
Clarissa Tassinari ${ }^{1}$ \\ Jéssica Cristianetti ${ }^{2}$ \\ Gabriele Zini de Oliveira ${ }^{3}$
}

\section{RESUMO}

Não obstante os direitos conquistados a partir da luta feminista, as relações sociais ainda são marcadas pela desigualdade de gênero. Especificamente no Brasil, a diferença na socialização de homens e mulheres reflete na inclusão delas no espaço político institucional, que, apesar de alguns avanços, ainda é um espaço majoritariamente marcado por homens brancos e proprietários, prejudicando a promoção de políticas públicas voltadas para as suas necessidades. Como metodologia para a construção do trabalho, adotou-se o método hermenêuticofenomenológico, justamente por enxergar o conhecimento de algo como acontecimento e fenômeno, bem como a técnica de pesquisa, que envolve a documentação indireta, através da pesquisa bibliográfica dos pressupostos teóricos de Nancy Fraser, além da pesquisa documental de relatórios construídos pelo ONU e pelo IPEA. Ao final do estudo, conclui-se que o patriarcalismo e o trabalho de cuidado atrelado à reprodução social são empecilhos para a inserção das mulheres no espaço político-institucional.

Palavras-chave: Desigualdade de gênero. Feminismo. Nancy Fraser. Política.

\footnotetext{
${ }^{1}$ Professora do Programa de Pós-Graduação (Mestrado), da Especialização (Stricto Sensu) e da Graduação em Direito da UNISINOS. Coordenadora do Mestrado Interinstitucional entre a UNISINOS e a FAG (Cascavel/PR). Doutora e Mestre em Direito Público pela Universidade do Vale do Rio dos Sinos (UNISINOS), com bolsa financiada pelo $\mathrm{CNPq}$, sob orientação do Prof. Dr. Lenio Luiz Streck. Pós-doutora em Direito Público (UNISINOS), com financiamento pela CAPES (PNPD).Universidade do Vale do Rio dos Sinos (UNISINOS). Paraná. Lattes:http://lattes.cnpq.br/5065376917812503 ORCID:https://orcid.org/0000-0002-4437-9556

E-mail:clatassinari@unisinos.br

2 Doutoranda em Direito Público pela Universidade do Vale dos Sinos - UNISINOS na linha de pesquisa: Hermenêutica, Constituição e Concretização de Direitos, Bolsista CNPq. Doutorado Sanduíche (Agosto/2019 a Março/2020) cursado na Penn State University, em State College/PA, bolsista CAPES/PDSE. Mestre em Direito Público pela Universidade do Vale dos Sinos - UNISINOS na linha de pesquisa: Hermenêutica, Constituição e Concretização de Direitos, foi Bolsista CAPES neste período, dissertação aprovada pela banca avaliadora com nota máxima. Pós-Graduada em Direito e Processo do Trabalho pelo Damásio Educacional. Bacharela em Direito pela Universidade de Caxias do Sul (2013/4). Universidade do Vale do Rio dos Sinos (UNISINOS). Paraná. Lattes:http://lattes.cnpq.br/7712487798685324 ORCID:https://orcid.org/0000-0002-8818-8081

E-mail:jessicacristianettiadv@gmail.com

${ }^{3}$ Bacharela em Direito pela Universidade do Vale dos Sinos (UNISINOS). Mestre em Direito Público pela Universidade do Vale dos Sinos (UNISINOS). Universidade do Vale do Rio dos Sinos (UNISINOS). Paraná. Lattes:http://lattes.cnpq.br/2525539821554136 ORCID:https://orcid.org/0000-0002-7209-665X E-mail:gabizini@hotmail.com.
} 


\begin{abstract}
Despite the rights achieveded from the feminist struggle, social relations are still marked by gender inequality. Specifically in Brazil, the difference in the socialization of men and women is reflected in their inclusion in the institutional political space, which, despite some advances, is still a space mostly marked by white men and owners, hindering the promotion of public policies aimed at their needs. As a methodology for the construction of the work, the hermeneutic-phenomenological method was adopted, precisely because it sees the knowledge of something as an event and phenomenon, as well as the research technique, which involves indirect documentation, through the bibliographic research of the theoretical assumptions of Nancy Fraser, in addition to documentary research of reports built by the UN and IPEA. At the end of the study, it is concluded that patriarchy and care work linked to social reproduction are obstacles to the insertion of women in the political-institutional space.
\end{abstract}

Keywords: Gender inequality. Feminism. Nancy Fraser. Policy.

\title{
INTRODUÇÃO
}

A desigualdade é uma das principais preocupações da comunidade internacional no século XXI, tendo em vista que as revoluções tecnológicas em concomitância com a globalização resultam a concentração de renda, acentuando, em consequência, o abismo social existente entre os indivíduos. Simultaneamente, as novas configurações do capitalismo financeirizado e a institucionalizando de projetos de austeridade fiscal acarretam o enxugamento do Estado na promoção de uma vida digna aos cidadãos, reduzindo drasticamente políticas públicas.

Apesar dessa compilação de fatores fragilizarem a vida da população como um todo, inegável que as mulheres são mais atingidas, sobretudo negras e indígenas, o que se justifica em decorrência das marcas estruturais do patriarcalismo ${ }^{4}$ na construção do Estado, das instituições e do papel social vinculado ao gênero. Se não bastasse, intensificando a subordinação, a insípida inserção das mulheres no âmbito político impede que haja construção de políticas e legislações pensadas por e para elas.

\footnotetext{
${ }^{4}$ Para Herrera Flores, o conceito de patriarcalismo observa as opressões interseccionais (sexo, raça, gênero, etnia e classe social) que violam diariamente a existência de mulheres. Há uma substituição da figura abstrata para a concreta, o que justifica em razão da relação existente na sociedade estratificada. Em que pese se entenda possuir melhor estruturação esse conceito, respeitando a utilização do termo patriarcado e as suas atualizações que se assemelham à proposta de Flores, entender-se-á patriarcalismo e patriarcado como sinônimos. FLORES, Joaquím Herrera. De habitaciones proprias y otros espacios negados: una teoría crítica de las opresiones patriarcales. Spain: Universidad de Deusto, 2005. p. 29.
} 
A partir do contexto delineado, observando o cenário de desigualdade enfrentado no Brasil e a invisibilização das demandas de brasileiras, o problema enfrentado neste trabalho é pensar em que medida as estruturas sociais, fundadas em parâmetros patriarcalistas e inseridas em um contexto capitalista, impedem a inserção das mulheres no espaço político-institucional.

Para a construção da pesquisa, elencou-se como objetivos específicos analisar os motivos que impedem a inserção das brasileiras no espaço político-institucional, a partir da pesquisa documental e da análise de dados de documentos formulados pela Organização das Nações Unidas (ONU) e pelo Instituto de Pesquisa Econômica Aplicada (IPEA); estudar a teoria da justiça de Nancy Fraser, especificamente os contrapúblicos subalternos, a reprodução social e a interpretação de necessidades.

Para construção do trabalho, adotou-se o método hermenêutico-fenomenológico, justamente por enxergar o conhecimento de algo como acontecimento e fenômeno, bem como a técnica de pesquisa, que envolve a documentação indireta, através da pesquisa bibliográfica dos pressupostos teóricos de Nancy Fraser, além da pesquisa documental de relatórios construídos pelo ONU e pelo IPEA.

\section{A INSERÇÃO DAS MULHERES NO CENÁRIO POLÍTICO BRASILEIRO}

A promoção de condições mais igualitárias entre os indivíduos é uma das principais preocupações da comunidade internacional, tendo em vista que os níveis de desigualdade social estão atrelados aos índices de violência dos países, bem como ao baixo desenvolvimento das economias $^{5}$. Por tais questões, em setembro de 2015, houve a reunião de líderes mundiais na sede da ONU para construção da Agenda 2030, que integra 17 Objetivos de Desenvolvimento Sustentável (ODS), entre os quais consta a promoção da igualdade de gênero ( $\left.5^{\circ} \mathrm{ODS}\right)$, que revela importância primordial para o êxito de toda a agenda, considerando o caráter transversal com os demais objetivos ${ }^{6}$.

A desigualdade de gênero está presente na vida de todas as mulheres, em que pese possua maior intensidade em razão das opressões interseccionais em relação a mulheres negras

\footnotetext{
${ }^{5}$ COMISSÃO ECONÔMICA PARA A AMÉRICA LATINA E CARIBE (CEPAL). Período de sessões, 37. 2018, Havana. A ineficiência da desigualdade. Santiago: CEPAL, 2018. Disponível em: https://repositorio.cepal.org/bitstream/handle/11362/43569/S1800303_pt.pdf?sequence=4\&isAllowed=y. Acesso em: 10 jul. 2019.

${ }^{6}$ QUAL É O SEU ODS?. In: PLATAFORMA AGENDA 2030. [S. l.]: Plataforma Agenda 2030, [2019?]. Disponível em: http://www.agenda2030.com.br/ods/5/. Acesso em: 11 jul. 2019.
} 
e indígenas. Na conjuntura atual, além da diferença salarial e da responsabilização pelo trabalho de cuidado, as mulheres ainda enfrentam a ausência de representação política. A fim de evidenciar essa disparidade, no ano de 2017, a ONU Mulheres, em parceria com a União Interparlamentar (UIP), realizou uma pesquisa para avaliar a participação de mulheres no parlamento, sendo que, entre 174 países, o Brasil ocupou a $154^{\mathrm{a}}$ posição no que se refere à representação feminina, enquanto no contexto dos 33 países latino-americanos e caribenhos ocupou a $32^{\mathrm{a}}$ posição. No que tange aos dados das últimas eleições, em que pese o número de mulheres eleitas tenha crescido $52,6 \%$ em relação a 2014 , a representatividade feminina ainda é extremamente baixa ${ }^{7}$.

O insípido nível da participação na institucionalidade é reflexo de a socialização das mulheres estar destinada ao cumprimento de afazeres vinculados à reprodução social, que são executados no âmbito doméstico. Em contrapartida, historicamente, a construção do espaço público foi destinado e protagonizados pelos homens, excluindo, em consequência, todos os sujeitos que não se enquadravam no padrão homem, hétero, branco e proprietário ${ }^{8}$. Em outras palavras, “A separação capitalista entre 'Estado' e 'sociedade' engendrou a oposição entre a esfera 'pública' e a esfera 'privada', que representa um mecanismo decisivo da opressão sexual"9.

A definição de um perfil para a atuação no âmbito institucional expõe a existência de hierarquias sociais que fragilizam a existência de uma sociedade efetivamente democrática, mantendo-se determinados sujeitos “[...] numa condição de sub-representação e de marginalidade no debate público, na construção de normas e políticas públicas" ${ }^{10}$. Ou seja, desde o nascimento, será determinado se a criança no futuro protagonizará uma vida no lar ou no espaço público.

Sobre essa questão, Fraser critica a separação do espaço público e privado promovida por Habermas, questionando quem efetivamente é reconhecido como cidadão? Na concepção de Fraser, ao contrário do filósofo alemão, esse papel é exclusivamente masculino, justamente

\footnotetext{
${ }^{7}$ NÚMERO de mulheres eleitas em 2018 cresce 52,6\% em relação a 2014. In: TRIBUNAL Superior Eleitoral, Brasília, DF, 08 mar. 2019. Disponível em: http://www.tse.jus.br/imprensa/noticias-tse/2019/Marco/numero-demulheres-eleitas-em-2018-cresce-52-6-em-relacao-a-2014. Acesso em: 31 jul. 2019.

${ }^{8}$ BIROLI, Flávia. Gênero e desigualdades: os limites da democracia no Brasil. 1. ed. São Paulo: Boitempo, 2018. p. 172.

${ }^{9}$ HIRSCH, 2010, p. 40 apud MATOS, Marlise; PARADIS, Clarisse Goulart. Desafios à despatriarcalização do Estado brasileiro. Cadernos Pagu, Campinas, n. 43, p. 75, dez. 2014. Disponível em: http://www.scielo.br/pdf/cpa/n43/0104-8333-cpa-43-0057.pdf. Acesso em: 05 ago. 2019.

${ }^{10}$ BIROLI, Flávia. Gênero e desigualdades: os limites da democracia no Brasil. 1. ed. São Paulo: Boitempo, 2018. p. 51.
} 
pelo fato de mulheres serem impedidas de participarem em igualdade com os homens na participação política. Além disso, socialmente, a interpretação das falas e denúncias de mulheres possuem filtro extremamente machista, o que se reflete em crimes de violência sexual, pois ainda há sujeitos que colocam em dúvida a palavra da vítima, especialmente quando existe a relativização do $n \tilde{a} o$.

Outro aspecto a ser observado são as consequências que a atribuição de papéis sociais implica na vida das mulheres, a pesquisadora Flávia Biroli afirma que a divisão sexual do trabalho é um dos principais fatores da exclusão de mulheres na participação política ${ }^{11}$. Isso porque "Quanto mais envolvidas estão com o trabalho doméstico cotidiano, menores e menos efetivos são os instrumentos de que dispõem para politizar as desvantagens que vivenciam e as hierarquias assim estruturadas" ${ }^{12}$. Segundo Fraser e Jaeggi:

[...] o ônus do trabalho reprodutivo ainda recai muito mais sobre os ombros das mulheres, que permanecem bem mais propensas do que os homens a chefiar domicílios sozinhas, com responsabilidades de cuidado primário e, provavelmente, tendo que cumprir dupla jornada, voltando para casa após um longo dia de trabalho pago para cozinhar, limpar, lavar roupa e cuidar de filhos e pais, mesmo quando têm companheiros masculinos ${ }^{13}$.

Em outras palavras, “[...] quem realiza trabalho doméstico enfrenta restrições no acesso a recursos políticos fundamentais, entre os quais estão: tempo livre, remuneração e redes de contato" 14 , ou seja, predominantemente, mulheres. De outro viés,

A participação na política institucional amplia os recursos para a politização e a ressemantização das experiências e dos problemas enfrentados pelas pessoas. Trata-se de um âmbito privilegiado das disputas, em que se definem quais são as necessidades prioritários e o que seria preciso para atende-las, assim como para a construção coletiva e a validação política dos interesses ${ }^{15}$.

Resultado da assimetria entre homens e mulheres, é a inexpressividade de políticas públicas construídas por e para elas, haja vista que há no Brasil uma democracia representativa,

${ }^{11}$ BIROLI, Flávia. Gênero e desigualdades: os limites da democracia no Brasil. 1. ed. São Paulo: Boitempo, 2018. p. 23.

${ }^{12}$ BIROLI, Flávia. Gênero e desigualdades: os limites da democracia no Brasil. 1. ed. São Paulo: Boitempo, 2018. p. 46-47.

${ }^{13}$ No original: Likewise, the onus of reproductive labor still falls overwhelmingly on the shoulders of women, who remain far more likely than men to be single heads of households, with primary care responsibilities, and far more likely, too, even when they have male partners, to work the "double shift," returning home from a long day of paid work to cook, clean, do laundry, and care for kids and parents.

${ }^{14}$ BIROLI, Flávia. Gênero e desigualdades: os limites da democracia no Brasil. 1. ed. São Paulo: Boitempo, 2018. p. 44.

${ }^{15}$ BIROLI, Flávia. Gênero e desigualdades: os limites da democracia no Brasil. 1. ed. São Paulo: Boitempo, 2018. p. 51 
em que os políticos eleitos representarão os interesses do povo na arena institucional. A fim de exemplificar a questão, cita-se a forma como o aborto ainda é debatido no Congresso Nacional: em que pese seja uma política fundamental para dignidade e preservação da vida de mulheres (considerando que hoje se trata de uma das principais causas de morte de mulheres jovens ${ }^{16}$ ), ainda se é debatido mediante argumentos religiosos ou sem qualquer vinculação à vida das mulheres.

Em igual sentido, cita-se a ausência de investimentos para políticas destinadas a suprir demandas do trabalho reprodutivo, como a construção de escolas de educação infantil ou espaços recreativos para idosos. A inexistência de atuação do Estado perante essas questões revela o interesse na reprivatização dos problemas sociais relacionados a mulheres, o que aprofunda a exclusão delas da vida pública ${ }^{17}$.

A neutralidade do Estado é, assim, verdadeiramente uma farsa, pois se assenta em dicotomias produzidas pela modernidade para manter lugares de poder hegemonizados, poder patriarcal e poder colonial: natural/civil, privado/público, mulher/indivíduo, com seus pressupostos contratualistas hierarquizadores e opressores $^{18}$.

Se o Estado é consumido pelo patriarcado, igualmente é definido pelo racismo, de modo que, embora as mulheres - aqui atribuindo sentido de coletividade - sejam subordinadas em decorrência dessa estrutura que define as relações sociais e institucionais, categorias como raça e classe aprofundam a precarização ${ }^{19}$ vivenciada por elas. Para exemplificar, consoante estudo realizado pelo Instituto de Pesquisa Econômica Aplicada (IPEA), mulheres possuem dificuldade para se inserirem no mercado de trabalho remunerado, o que se evidencia com o fato da taxa de participação feminina, entre o período do ano de 1995 a 2015, oscilar entre 54\% a 55\%, o que significa que a metade das mulheres ativas não ocupam cargos remunerados. No

16 CÁSSIA, Sávia; SOUZA, Heloísa de. "Aborto é a quarta causa de morte materna no Brasil”, afirma pesquisadora. Brasil de Fato, Campina Grande, 31 jul. 2018. Disponível em: https://www.brasildefato.com.br/2018/07/31/aborto-e-a-quarta-causa-de-morte-materna-no-brasil-afirmapesquisadora/. Acesso em: 06 ago. 2019.

${ }^{17}$ BIROLI, Flávia. Gênero e desigualdades: os limites da democracia no Brasil. 1. ed. São Paulo: Boitempo, 2018. p. 50.

18 MATOS, Marlise; PARADIS, Clarisse Goulart. Desafios à despatriarcalização do Estado brasileiro. Cadernos Pagu, Campinas, n. 43, p. 87, dez. 2014. Disponível em: http://www.scielo.br/pdf/cpa/n43/0104-8333-cpa-43-0057.pdf. Acesso em: 05 ago. 2019.

${ }^{19}$ Nesse escrito, a precariedade será utilizada de acordo com o preceituado por Butler (2015). A precariedade ou a condição de precarização - traduz-se numa subordinação das condições políticas do sujeito-humano, em que uma parcela (ou parte de um grupo humano) é condenada ao sofrimento, à barbárie, e há uma subsunção ao espaço do silêncio, da opacidade, do vazio, das precárias redes sociais e econômicas do estado. Desse modo, esses grupos - como ocorre com as mulheres - estão mais expostos à violência, ao risco e à vulnerabilidade, não social, mas, sobretudo, política. São corpos que importam menos, vidas precárias que se submetem, diariamente, às injustiças, aos não reconhecimentos e às invisibilidades. (BUTLER, 2015). 
ano de 2015, “[...] a taxa de desocupação feminina era de 11,6\% - enquanto a dos homens foi de 7,8\%. No caso das mulheres negras, a proporção chegou a 13,3\% (a dos homens negros, $8,5 \%)^{״ 20}$, contudo se for utilizada como categoria de análise mulheres negras com ensino médio completo ou incompleto (nove a 11 anos de estudos) a taxa aumenta para $17,4 \%{ }^{21}$.

Complementando os dados, a ocupação de postos de trabalho em ambientes precarizados é majoritariamente ocupado por mulheres negras (39\%), seguidas pelos homens negros $(31,6 \%)$, pelas mulheres brancas $(27 \%)$ e, por último, homens brancos $(20,6 \%)^{22}$.Outro dado que chama atenção é que, segundo estudos citados no relatório Think Olga (Mulheres, 2020), as mulheres negras representam 3,7 milhões das 5,7 milhões de domésticas, sendo que $70 \%$ dessas não tem carteira assinada, ou seja, estão na informalidade. Ou seja, “[...] o Estado não pode ser visto como entidade unitária e, portanto, ele não irá 'tocar' a todas as mulheres (e à população negra) brasileiras da mesma maneira e muito menos de modo universal e totalizante" ${ }^{23}$.

A condição das mulheres negras na sociedade brasileira é ainda legado da escravidão, de modo que, se inexpressiva a participação de mulheres brancas no espaço institucional, a representatividade se agrava quando analisada a eleição de mulheres negras. Todavia, se na esfera pública oficial não há abertura para elas, inegável que a sua atuação política em arenas paralelas se torna cada dia mais evidente, o que ocorre também mediante alianças interseccionais que intensificam a luta feminista. Assim, apesar de não ser possível a inserção no espaço institucional, a coletividade de mulheres está formando arenas políticas paralelas como forma de tornar as suas reivindicações um assunto político ${ }^{24}$.

Esse engajamento refuta a falácia de que a ausência de representatividade é resultado do desinteresse ou do fraco envolvimento político das mulheres, sendo certo que, na verdade, a

\footnotetext{
${ }^{20}$ INSTITUTO DE PESQUISA ECONÔMICA APLICADA (IPEA). Retrato das desigualdades de gênero e raça $-1995 \quad$ a $2015 . \quad$ Brasília, $2015 . \quad$ Disponível em: http://www.ipea.gov.br/portal/images/stories/PDFs/170306_retrato_das_desigualdades_de_genero_raca.pdf. Acesso em: 06 ago. 2019.

${ }^{21}$ INSTITUTO DE PESQUISA ECONÔMICA APLICADA (IPEA). Retrato das desigualdades de gênero e raça $\quad-\quad 1995 \quad$ a $2015 . \quad$ Brasília, $2015 . \quad$ Disponível em: http://www.ipea.gov.br/portal/images/stories/PDFs/170306_retrato_das_desigualdades_de_genero_raca.pdf. Acesso em: 06 ago. 2019.

22 PINHEIRO, Luana Simões et al. Mulheres e trabalho: breve análise do período 2004-2014. IPEA: Brasília, 2016.

23 MATOS, Marlise; PARADIS, Clarisse Goulart. Desafios à despatriarcalização do Estado brasileiro. Cadernos Pagu, Campinas, n. 43, p. 71, dez. 2014. Disponível em: http://www.scielo.br/pdf/cpa/n43/0104-8333-cpa-43-0057.pdf. Acesso em: 05 ago. 2019.

${ }^{24}$ BIROLI, Flávia. Gênero e desigualdades: os limites da democracia no Brasil. 1. ed. São Paulo: Boitempo, 2018. p. 174.
} 
atuação é dificultada em decorrência dos padrões definidores da constituição do espaço público e do peso da reprodução social colocado nos ombros femininos. Até porque "[...] há diferença entre lidar com as formas de silenciamento que constituem o ambiente político e definem suas fronteiras e presumir algum tipo de silêncio, como se as vozes contestatórias não existissem"25. Em síntese,

Os movimentos feministas têm atuado de 'fora' (exercendo pressão a partir das ruas) e 'dentro' do Estado, participando da construção de políticas e de novos marcos de referência para as democracias contemporâneas no âmbito estatal nacional e em organizações e espaços transnacionais ${ }^{26}$.

Esse ímpeto combativo das mulheres fortalece o processo de despatriarcalização do Estado, considerando que há o confronto do movimento feminista em face das estruturas de subordinação ${ }^{27}$. Como referido por Matos, atribui-se o significado de despatriarcalização a construção de "[...] estratégias e mecanismos de descolonização patriarcal e racial do Estado brasileiro e da sua forma de gestão pública, com vistas a reforçar uma nova etapa que tenha foco na conquista de resultados cívicos de políticas públicas"28, ou seja, "Trata-se de pensar um formato de Estado, finalmente, voltado para a promoção da justiça social e da cidadania inclusiva de todas e todos em nosso país"29.

Frisa-se que uma das importantes conquistas de feministas nessa ordem ocorreu na construção da Constituição de 1988, considerando que a promoção da igualdade de gênero se tornou um marco regulatório do Estado, consequência da pressão estabelecida pelos movimentos sociais, em especial da Carta das Mulheres aos Constituintes ${ }^{30}$ realizada, no ano

${ }^{25}$ BIROLI, Flávia. Gênero e desigualdades: os limites da democracia no Brasil. 1. ed. São Paulo: Boitempo, 2018. p. 175.

${ }^{26}$ BIROLI, Flávia. Gênero e desigualdades: os limites da democracia no Brasil. 1. ed. São Paulo: Boitempo, 2018. p. 175.

27 MATOS, Marlise; PARADIS, Clarisse Goulart. Desafios à despatriarcalização do Estado brasileiro. Cadernos Pagu, Campinas, n. 43, p. 68, dez. 2014. Disponível em: http://www.scielo.br/pdf/cpa/n43/0104-8333-cpa-43-0057.pdf. Acesso em: 05 ago. 2019.

28 MATOS, Marlise; PARADIS, Clarisse Goulart. Desafios à despatriarcalização do Estado brasileiro. Cadernos Pagu, Campinas, n. 43, p. 71, dez. 2014. Disponível em: http://www.scielo.br/pdf/cpa/n43/0104-8333-cpa-43-0057.pdf. Acesso em: 05 ago. 2019.

29 MATOS, Marlise; PARADIS, Clarisse Goulart. Desafios à despatriarcalização do Estado brasileiro. Cadernos Pagu, Campinas, n. 43, p. 71, dez. 2014. Disponível em: http://www.scielo.br/pdf/cpa/n43/0104-8333-cpa-43-0057.pdf. Acesso em: 05 ago. 2019.

30 “'A 'Carta' é um documento representativo da radicalidade e da abrangência das demandas encampadas naquele momento. Seu preâmbulo prometia desobediência civil, ainda que indiretamente, por meio da citação de palavras de Abgail Adams, defensora dos direitos das mulheres nos Estados Unidos no século XIX e esposa do segundo presidente estadunidense, John Adams: 'Se não for dada a devida atenção às mulheres, estamos decididas a fomentar uma rebelião e não nos sentiremos obrigadas a cumprir leis para as quais não tivemos voz nem representação'. Nos seis eixos específicos em que foram organizadas as reivindicações - família, trabalho, saúde, educação e cultura, violência, questões nacionais e internacionais -, os problemas de gênero apareciam entrelaçados aos de classe, raça e sexualidade, com atenção à propriedade de terra no campo, aos direitos 
de 1986, no Encontro Nacional Mulher e Constituinte e entregue ao Ulisses Guimarães em $1987^{31}$.

Em igual sentido, existiram importantes avanços, apesar de insuficientes, na efetivação de políticas públicas voltadas às mulheres durante o período dos governos petistas, tendo em vista que houve o diálogo (ou ao menos uma tentativa) entre os movimentos feministas e a gestão Lula e Dilma, o que resultou, por exemplo, na criação da Secretaria Especial de Políticas para Mulheres ${ }^{32}$. Destarte, a luta pela despatriarcalização do Estado e, em consequência, a inserção de mulheres no espaço institucional, é fundamental para minimização das desigualdades sociais, tendo em vista que se trata de "[...] um recurso de poder em si mesmo, na medida em que é capaz de mobilizar outros recursos (sejam materiais, sejam simbólicoculturais e, claro, políticos) de poder"33.

Para além da luta no âmbito nacional, a formação de arenas discursivas transnacionais reflete no cenário legislativo brasileiro. Um importante marco ocorreu em setembro de 1995, quando a China sediou a $4^{\circ}$ Conferência Mundial sobre a Mulher, sendo que o Brasil, entre 189 países, comprometeu-se a consolidar ações afirmativas para a inclusão das mulheres na política. A materialização desse compromisso ocorreu com a promulgação da Lei $n^{\circ}$ 9.100/95, que reserva cota mínima para candidaturas de mulheres nos pleitos eleitorais. Entre as mudanças ocorridas ao longo dos anos, revela-se a alteração de 2009 como a principal, tendo em vista que a Lei $\mathrm{n}^{\circ} 12.034 / 09$ alterou a reserva para preencher os cargos, tornando, portanto, obrigatória a presença de candidaturas de mulheres em cada partido político, sendo determinada, ainda, a reserva de no mínimo $10 \%$ de propaganda eleitoras para as candidatas mulheres, além da destinação de 5\% dos valores do Fundo Partidário ${ }^{34}$. Ademais, no ano de 2018, a ministra Rosa Weber do Superior Tribunal Eleitoral (TSE) determinou que “[...] o Fundo Especial Eleitoral deve aplicar a mesma norma do Fundo Partidário para o Fundo Especial de Campanha Eleitoral

trabalhistas e a exigências específicas de acesso universal à saúde e à seguridade”. BIROLI, Flávia. Gênero e desigualdades: os limites da democracia no Brasil. 1. ed. São Paulo: Boitempo, 2018. p. 182.

${ }^{31}$ BIROLI, Flávia. Gênero e desigualdades: os limites da democracia no Brasil. 1. ed. São Paulo: Boitempo, 2018. p. 182.

${ }^{32}$ BIROLI, Flávia. Gênero e desigualdades: os limites da democracia no Brasil. 1. ed. São Paulo: Boitempo, 2018. p. 189.

33 MATOS, Marlise; PARADIS, Clarisse Goulart. Desafios à despatriarcalização do Estado brasileiro. Cadernos Pagu, Campinas, n. 43, p. 73, dez. 2014. Disponível em: http://www.scielo.br/pdf/cpa/n43/0104-8333-cpa-43-0057.pdf. Acesso em: 05 ago. 2019.

${ }^{34}$ MELO, Hildete Pereira de. A política de cotas para as mulheres no Brasil: importância e desafios para avançar. In: Gênero e Número, São Paulo, 13 set. 2018. Disponível em: http://www.generonumero.media/apolitica-de-cotas-para-as-mulheres-no-brasil-importancia-e-desafios-para-avancar/. Acesso em: 03 ago. 2019. 
e destinar o mínimo de $30 \%$ para as candidaturas de mulheres, em todos os níveis da campanha eleitoral $[\ldots]^{\prime 3}$.

A implementação das cotas eleitorais é reflexo da insuficiência da democracia liberal, isto é, a ineficiência do "[...] indivíduo como única unidade política legítima e o relativo isolamento da arena política (caracterizada pela igualdade formal entre os cidadãos) em relação às injustiças sociais" 36 . "O conflito desta posição com o liberalismo político reside na defesa do direito das mulheres - isto é, de um grupo - a terem seus interesses representados na arena política" ${ }^{\text {37 }}$, tendo em vista que esse sistema possui como núcleo o individualismo.

Embora as cotas sejam um passo para a despatriarcalização do Estado, além de confrontar a eficiência do caráter liberal da democracia brasileira, ainda são insuficientes. Isso porque, em que pese as cotas de gênero existam há anos, os seus reflexos não são vivenciados, considerando a inexpressiva candidatura e eleição de mulheres para cargos no executivo e legislativo ${ }^{38}$. Logo, além de políticas voltadas para a expansão da inserção das mulheres em cargos públicos, imprescindível que as estruturas sociais que causam a subordinação feminina sejam transformadas consoante a reivindicação da luta feminista.

\section{INTERPRETAÇÃO DAS NECESSIDADES E CONTRAPÚBLICOS SUBALTERNOS FEMINISTAS}

Diante das estruturas sociais, existem disputas para que determinadas demandas se tornem uma questão política a ser debatida no âmbito público, sendo que a privatização de reinvidicações de minorias é uma das formas de manutenção da dominação e de hierarquias sociais. Um exemplo que evidencia a premissa, é a violência doméstica, tendo em vista que, inicialmente, era tratada como se fosse um problema privado, sem interferência, portanto, do Estado. Contudo, em decorrência da problematização perfectibilizada por movimentos

\footnotetext{
${ }^{35}$ MELO, Hildete Pereira de. A política de cotas para as mulheres no Brasil: importância e desafios para avançar. In: Gênero e Número, São Paulo, 13 set. 2018. Disponível em: http://www.generonumero.media/apolitica-de-cotas-para-as-mulheres-no-brasil-importancia-e-desafios-para-avancar/. Acesso em: 03 ago. 2019. ${ }^{36}$ MIGUEL, Luís Felipe. Teoria política feminista e liberal: o caso das cotas de representação. Revista Brasileira de Ciências Sociais, v. 15, n. 44, p. 91, out. 2000. Disponível: http://www.scielo.br/pdf/rbcsoc/15n44/4149.pdf. Acesso em: 05 ago. 2019.

37 MIGUEL, Luís Felipe. Teoria política feminista e liberal: o caso das cotas de representação. Revista Brasileira de Ciências Sociais, v. 15, n. 44, p. 94, out. 2000 . Disponível: http://www.scielo.br/pdf/rbcsoc/v15n44/4149.pdf. Acesso em: 05 ago. 2019.

${ }^{38}$ Importante refletir sobre uma questão trazida por Pinto (2014, p. 155): “as feministas podem não estar lutando para o aumento do número de mulheres na política, mas pensando em mulheres que sejam capazes, por sua militância, de colocar em público as demandas do movimento".
} 
feministas, tornou-se um problema político, o que, inclusive, motivou, no Brasil, a promulgação da Lei ${ }^{\circ} 11.340 / 2006$, que criou mecanismos para coibir a violência doméstica e familiar contra a mulher.

Além das disputas sobre o que é político, ainda há embate acerca da interpretação das necessidades, ou seja, quais respostas serão apresentadas em relação às reivindicações sociais. A política de interpretação de necessidade se consolida em três etapas: em primeiro, “[...] es la lucha por establecer o negar el estatus político de una necesidad dada, la lucha por validar la necesidad como um asunto de interés político legítimo o situarla como un asunto no político"39; em segundo, "[...] es el debate acerca de la interpretación de la necesidad, la lucha por el poder de definirla y, de ese modo, por determinar qué la satisfaria" ${ }^{40}$; por fim, em terceiro, “[...] es la lucha acerca de la satisfacción de la necesidad, la lucha por garantizar o denegar uma ayuda"41.

Nesses termos, não se revela suficiente tornar o problema político, mas disputar igualmente quais as respostas serão apresentadas a essa questão. Basicamente, o embate que se forma é o confronto de manifestações entre os sujeitos afetados em face do grupo dominante. De um lado, "Lo grupos dominantes articulan las interpretaciones de las necesidades con la intención de excluir, desactivar y/o absorber las contrainterpretaciones"42; em contrapartida, "Los grupos subordinados o de oposición, por el contrario, articulan interpretaciones de necesidades pensadas para cuestionar, desplazar y/o modificar las dominantes"43.

Como se evidencia, esse processo de interpretação das necessidades é relevante, porque determinadas respostas apresentadas a problemas sociais intensificam as hierarquias sociais ou podem causar a manutenção dos padrões que foram a causa daquela subordinação. Por tal razão, a interpretação das necessidades não pode ser considerada como um fim em si mesmo, mas deve ser o ponto de partida para a problematização das causas das injustiças. Até porque as sociedades atuais não são marcadas apenas pela pluralidade, mas são “[...]

${ }^{39}$ FRASER, Nancy. Fortunas del feminismo. Quito: Instituto de Altos Estudios nacionales Del Ecuador, 2015. p. 79.

${ }^{40}$ FRASER, Nancy. Fortunas del feminismo. Quito: Instituto de Altos Estudios nacionales Del Ecuador, 2015. p. 79 .

${ }^{41}$ FRASER, Nancy. Fortunas del feminismo. Quito: Instituto de Altos Estudios nacionales Del Ecuador, 2015. p. 79.

42 FRASER, Nancy. Fortunas del feminismo. Quito: Instituto de Altos Estudios nacionales Del Ecuador, 2015. p. 82

${ }^{43}$ FRASER, Nancy. Fortunas del feminismo. Quito: Instituto de Altos Estudios nacionales Del Ecuador, 2015. p. 82 
estratificadas, diferenciadas en grupos sociales com distintos estatus, poder y acceso a recursos, atravesadas por ejes de desigualdad dominantes por razones de clase, sexo, raza, etnia y edad"44.

A fim de exemplificar a questão, cita-se a situação de uma mulher negra que está desempregada e possui dificuldades na sua recolocação no mercado de trabalho. Superficialmente, é possível indicar que a sua dificuldade é decorrente da crise que assola a economia do país. Contudo, se a situação for efetivamente problematizada, é possível atribuir essa condição ao racismo estrutural, a ausência de políticas públicas destinadas ao trabalho do cuidado (como a inexistência de vagas em creches públicas, se ela for mãe ou responsável pelo cuidado de algum parente). Como se evidencia, inúmeras outras questões surgem quando um problema social é tratado com seriedade e não de forma genérica, podendo, assim, tomar dimensões muito além do disseminado pelo discurso padrão. Portando, "Importa visualizar que os detalhes da formulação de uma necessidade são complexos, gerando reivindicações específicas diversas que se vinculam em cadeias de relações"45.

O grande ponto, portanto, é saber como politizar as demandas sociais na atualidade. Para Fraser, a resposta a essa questão perpassa necessariamente pela fomentação do debate em arenas discursivas formadas em paralelo à esfera pública oficial por sujeitos afetados que articulam forças entre si. Em suma, após a identificação das necessidades, os afetados se unem com o propósito de provocar rupturas com os mecanismos que promovem injustiças, iniciando, paulatinamente, a articulação de discursos acerca dos problemas sociais que lhes acometem. Por conseguinte, os afetados impulsionam o debate público sobre aquela necessidade a partir da sua perspectiva, formando-se, em consequência, o discurso contra hegemônico ${ }^{46}$.

Quando ocorre a junção dos afetados para a promoção de críticas ao padrão social despótico hegemônico, Fraser identifica e denomina o grupo como contrapúblicos subalternos ${ }^{47}$. A produção do contra discurso é verbalizada com o desígnio de reconhecimento

\footnotetext{
${ }^{44}$ FRASER, Nancy. Fortunas del feminismo. Quito: Instituto de Altos Estudios nacionales Del Ecuador, 2015. p. 81.

${ }^{45}$ SILVA, Enrico Paternostro Bueno da. A teoria social crítica de Nancy Fraser: necessidade, feminismo e justiça, Brasil. 2013. 257 f. Dissertação (Mestrado em Sociologia) - Programa de Pós-Graduação em Sociologia do Instituto de Filosofia e Ciências Humanas da Universidade Estadual de Campinas (Unicamp), Campinas, 2013. Disponível em: http://www.bibliotecadigital.unicamp.br/document/?code=000919847. Acesso em: 06 ago. 2019. p. 34.

46 BUNCHAFT, Maria Eugênia. Ativismo judicial e grupos estigmatizados: filosofia constitucional do reconhecimento. 2. ed. Curitiba: Juruá, 2015. p. 88-92.

${ }^{47}$ FRASER, Nancy. Fortunas del feminismo. Quito: Instituto de Altos Estudios nacionales Del Ecuador, 2015. p. 75
} 
e de projeção da esfera privada para o público das reivindicações dos grupos, bem como pela ruptura de estereótipos estigmatizantes ${ }^{48}$. Nas palavras de Fraser,

Propongo llamarlos contra-públicos subalternos para así poder señalar que son terrenos discursivos paralelos en donde los miembros de los grupos sociales subordinados inventan y hacen circular contradiscursos, que, al mismo tiempo, les permiten formular interpretaciones de oposición acerca de sus identidades, intereses y necesidades ${ }^{49}$.

Para melhor elucidar, a teórica exemplifica a construção a partir do exemplo de trabalhadoras negras que se conscientizam da sua situação de exploração em virtude do sistema capitalista que estruturalmente é racista e patriarcal. Assim, inicialmente, as trabalhadoras questionam as estruturas sociais que precarizam a suas vidas e o porquê isso não é debatido como um problema político. Por conseguinte, essas mulheres, ao debaterem sobre a sua situação, apresentam alternativas e soluções para superação dessa precarização. Por fim, elas vão difundir suas propostas, formando, assim, uma arena discursiva paralela à esfera pública oficial, confrontando padrões hegemônicos e apresentando uma nova forma de interpretação das suas necessidades ${ }^{50}$.

Nesse processo, em que os contrapúblicos confrontam o status quo, é primordial que haja o confronto das respostas que apresentam soluções em que se tenha a reprivatização do problema ou haja a identificação dos reivindicantes como vítimas. A última situação ocorre corriqueiramente quando o Estado, mediante a atuação de profissionais, apresenta soluções às reivindicações, sem, contudo, haver análise acerca dos pleitos da forma como foram realizados. Ainda mais grave, é quando as medidas efetivadas tratam o problema debatido como se fosse algo relacionado à esfera individual, ignorando, assim, o caráter coletivo ${ }^{51}$. Em outras palavras,

Como resultado de estas redifiniciones de los expertos, aquellos cuyas necesidades están en custión se reposicionan. Se convierten em 'casis' individuales en lugar de membros de grupos sociales os participantes em movimentos políticos. Además, son convertidos em sujetos pasivos, posicionados como potenciales receptores de servicios predefinidos y no como agentes implicados en la interpretación de sus necesidades y em el modelado de sus condiciones de vida ${ }^{52}$.

${ }^{48}$ FRASER, Nancy. Repensar el ámbito público: una contribución a la crítica de la democracia realmente existente. [S.1.], Metis Productos Culturales S.A. de C.V., 1993. p. 30-37.

${ }^{49}$ FRASER, Nancy. Repensar el ámbito público: una contribución a la crítica de la democracia realmente existente. [S.1.], Metis Productos Culturales S.A. de C.V., 1993. p. 41.

${ }^{50}$ FRASER, Nancy. Fortunas del feminismo. Quito: Instituto de Altos Estudios nacionales Del Ecuador, 2015. p. 90 .

51 FRASER, Nancy. Fortunas del feminismo. Quito: Instituto de Altos Estudios nacionales Del Ecuador, 2015. p. 92-94.

52 FRASER, Nancy. Fortunas del feminismo. Quito: Instituto de Altos Estudios nacionales Del Ecuador, 2015. p. 94. 
Em complemento a essas proposições, analisando a importância de que todas as pessoas tenham oportunidade de interagir na sociedade com igualdade, Fraser desenvolveu a teoria tridimensional de justiça, cujo cerne é a paridade participativa, que "[...] significa a condição de um par, de se estar em igual condição de ser um par, de se estar em igual condição

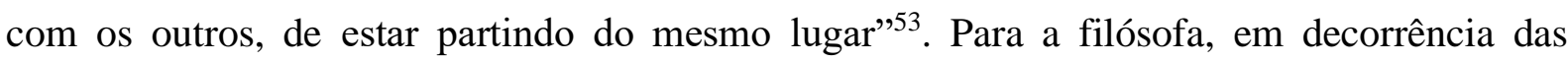
estruturas sociais, os sujeitos podem ser impedidos de participar em igualdade nas relações privadas ou na esfera pública em decorrência de injustiças econômicas (redistribuição), culturais (reconhecimento) e políticas (representação).

Em relação às injustiças econômicas os indivíduos são impedidos de “[...] participar efetivamente das estruturas econômicas, que lhes rejeitam os meios necessários para interagir com outros como iguais; nesse caso, sofrem de injustiça distributiva ou má-distribuição" ${ }^{\circ 4}$; de outro lado, quanto às injustiças culturais os sujeitos estão impossibilitados de "[...] interagir em termos de paridade por meio de hierarquias institucionalizadas de valor cultural que lhes nega a posição necessária; nesse caso, eles sofrem de desigualdade em termos de status ou malreconhecimento" ${ }^{55}$; por fim, no que tange às injustiças políticas os sujeitos são impedidos de “[...] praticar uma participação plena por regras estabelecidas, negando-lhes a igualdade em deliberações públicas e na tomada de decisões democráticas" $" 56$.

Segundo o entendimento de Fraser, a representação relaciona-se diretamente com as reivindicações por reconhecimento e por redistribuição, pois a dimensão política está interligada aos fatores que originam tais injustiças sociais, isto é, contra quem e por quem devem ser realizadas as reivindicações e $o$ que deve ser efetivado para apaziguar os problemas sociais enfrentados ${ }^{57}$. Nesse sentido, "Superar a injustiça significa desmantelar os obstáculos institucionalizados que impedem alguns sujeitos de participarem, em condições de paridade com os demais, como parceiros integrais da interação social" 58 .

\footnotetext{
${ }^{53}$ FRASER, Nancy. Reconhecimento sem ética. Lua Nova, São Paulo, n. 70, p. 118, 2007. Disponível em: http://www.scielo.br/pdf/ln/n70/a06n70.pdf. Acesso em: 06 ago. 2019.

54 FRASER, Nancy. Justiça anormal. Revista da Universidade de Direito de São Paulo, v. 108, p. 752, jan./dez. 2013. Disponível em: http://www.revistas.usp.br/rfdusp/article/view/68001. Acesso em: 06 ago. 2019.

${ }_{55}$ FRASER, Nancy. Justiça anormal. Revista da Universidade de Direito de São Paulo, v. 108, p. 752, jan./dez. 2013. Disponível em: http://www.revistas.usp.br/rfdusp/article/view/68001. Acesso em: 06 ago. 2019. ${ }^{56}$ FRASER, Nancy. Justiça anormal. Revista da Universidade de Direito de São Paulo, v. 108, p. 752, jan./dez. 2013. Disponível em: http://www.revistas.usp.br/rfdusp/article/view/68001. Acesso em: 06 ago. 2019. ${ }^{57}$ FRASER, Nancy. Reenquadrando a justiça em um mundo globalizado. Lua Nova, São Paulo, n. 77, p. 19, 2009. Disponível em: http://www.scielo.br/scielo.php?pid=S010264452009000200001\&script=sci_abstract\&tlng=pt. Acesso em: 06 ago. 2019.

${ }^{58}$ FRASER, Nancy. Reenquadrando a justiça em um mundo globalizado. Lua Nova, São Paulo, n. 77, p. 19, 2009. Disponível em: http://www.scielo.br/scielo.php?pid=S0102-64452009000200001\&script=sci abstract\&tlng=pt. Acesso em: 06 ago. 2019.
} 
Logo, a falsa representação se consolida quando “[...] as regras de decisão política equivocadamente negam a alguns dos incluídos a chance de participar plenamente, como pares [...]"59, o que se evidencia ao analisar a sub-representação de mulheres na política brasileira. Para além disso, a preocupação central da teórica reside na necessidade de existir paridade participativa entre os indivíduos, com o intento de evitar injustiças sociais decorrentes da subordinação de status, classe ou falsa representação.

Dessa maneira, não há como negar que a presença de representantes mulheres que até então constituíam grupo totalmente excluído da esfera pública é essencial para a defesa dos direitos femininos. Contudo, políticas de representação devem ser unidas às políticas de redistribuição e reconhecimento, visto que as mulheres sofrem com as três espécies de desigualdades, sendo uma influenciada pelas outras. (PINTO, 1999, p. 69).

Diante do cenário brasileiro, em que é negado às mulheres condições para participação efetiva da política institucional, a teoria de Nancy Fraser revela alcance teórico para construção de soluções a essas injustiças sociais. A partir da sua construção, inegável que a inserção de mulheres - como também de demais minorias sociais - é fundamental para fortalecimento da democracia, sob pena do âmbito público estar fadado aos discursos de sujeitos que se enquadram no padrão dominante.

\section{CONSIDERAÇÕES FINAIS}

Analisando o cenário brasileiro, a construção do modelo teórico de Nancy Fraser é um importante mecanismo para a construção de caminhos para emancipação das mulheres. Isso porque a principal causa da subordinação e exploração das brasileiras se consolida em decorrência das estruturas sociais (calcadas no patriarcalismo) regularem as relações privadas e a esfera pública. Nesse sentido, a busca pela paridade participativa das mulheres perpassa pela superação das injustiças sociais vivenciadas no âmbito econômico, cultural e, em especial, político.

Nesse intento, confirmando-se a hipótese apresentada, a inserção de mulheres no espaço político brasileiro está condicionada à desconstrução dos papeis de gênero construídos historicamente, ou seja, não mais ser destinado a elas o espaço doméstico e a responsabilização

\footnotetext{
${ }^{59}$ FRASER, Nancy. Reenquadrando a justiça em um mundo globalizado. Lua Nova, São Paulo, n. 77, p. 21, 2009. Disponível em: http://www.scielo.br/scielo.php?pid=S0102-64452009000200001\&script=sci abstract\&tlng=pt. Acesso em: 06 ago. 2019.
} 
pelo trabalho reprodutivo não remunerado, tampouco a eles ser reservado o protagonismo na vida política. Nessa senda, é primordial o rompimento dos obstáculos que impedem a interferência das reivindicações e do discurso contra hegemônico feminista na políticainstitucional.

Nesses termos, repensar as estruturas sociais é requisito para confrontar a desigualdade social no Brasil, que se perfectibiliza hoje como o principal problema para o desenvolvimento da democracia e relações igualitárias. Além disso, a atuação consciente ${ }^{60}$ delas no espaço político institucional é importante para a construção de medidas afirmativas com caráter de transformação social, a fim de que haja a emancipação de todas as brasileiras independentemente de classe ou raça. Em suma, consoante elencado por Flávia Biroli, é preciso desmantelar a divisão sexual do trabalho e os limites existentes entre o público e o privado para o rompimento das causas de subordinação das brasileiras.

\section{REFERÊNCIAS}

BIROLI, Flávia. Gênero e desigualdades: os limites da democracia no Brasil. 1. ed. São Paulo: Boitempo, 2018.

BUNCHAFT, Maria Eugênia. Ativismo judicial e grupos estigmatizados: filosofia constitucional do reconhecimento. 2. ed. Curitiba: Juruá, 2015.

CÁSSIA, Sávia; SOUZA, Heloísa de. "Aborto é a quarta causa de morte materna no Brasil", afirma pesquisadora. Brasil de Fato, Campina Grande, 31 jul. 2018. Disponível em: https://www.brasildefato.com.br/2018/07/31/aborto-e-a-quarta-causa-de-morte-materna-nobrasil-afirma-pesquisadora/. Acesso em: 06 ago. 2019.

COMISSÃO ECONÔMICA PARA A AMÉRICA LATINA E CARIBE (CEPAL). Período de sessões, 37., 2018, Havana. A ineficiência da desigualdade. Santiago: CEPAL, 2018. Disponível em: https://repositorio.cepal.org/bitstream/handle/11362/43569/S1800303_pt.pdf? sequence $=4 \&$ isAllowed=y. Acesso em: 10 jul. 2019.

D’AVILA, Manuela Pinto Vieira. Mulheres implementam mais políticas públicas para mulheres? O efeito da presença de mulheres no comando do poder executivo municipal para a

\footnotetext{
${ }^{60} \mathrm{O}$ objetivo do presente trabalho era analisar os entraves existentes na inserção de mulheres na vida política. Contudo, embora transcenda o problema proposto, ressalta-se que a eleição de mulheres que não possuem o comprometimento com a emancipação das demais em nada auxiliaria na transformação do status quo. Para análise da questão, recomenda a leitura do livro Democracia e representação: territórios em disputa de autoria de Luís Felipe Miguel, bem como a dissertação de Manuela D’avila, Mulheres implementam mais políticas públicas para mulheres? O efeito da presença de mulheres no comando do Poder Executivo para a implementação de políticas públicas com recorte de gênero.
} 
implementação de políticas públicas com recorte de gênero nos municípios brasileiros, Brasil. 2018. 66 f. Dissertação (Mestrado em Políticas Públicas) - Programa de Pós-Graduação em Políticas Públicas (UFRGS), Porto Alegre, 2018. Disponível em: https://lume.ufrgs.br/handle/10183/189845?locale-attribute=es. Acesso em: 06 ago. 2019.

DESLAURIERS, Jean-Pierre. A indução analítica. In: POUPART, Jean et al. A pesquisa qualitativa: enfoques epistemológicos e metodológicos. Petrópolis: Vozes, 2014. p. 337-352.

FLORES, Joaquím Herrera. De habitaciones proprias y otros espacios negados: una teoría crítica de las opresiones patriarcales. Spain: Universidad de Deusto, 2005.

FRASER, Nancy. Fortunas del feminismo. Quito: Instituto de Altos Estudios nacionales Del Ecuador, 2015.

FRASER, Nancy. Justiça anormal. Revista da Universidade de Direito de São Paulo, v. 108, p. 752, jan./dez. 2013. Disponível em: http://www.revistas.usp.br/rfdusp/article/view/68001. Acesso em: 06 ago. 2019.

FRASER, Nancy. Reconhecimento sem ética. Lua Nova, São Paulo, n. 70, p. 101- 138, 2007. Disponível em: http://www.scielo.br/pdf/ln/n70/a06n70.pdf. Acesso em: 06 ago. 2019.

FRASER, Nancy. Reenquadrando a justiça em um mundo globalizado. Lua Nova, São Paulo, n. 77 , p. 11-39, 2009. Disponível em: http://www.scielo.br/scielo.php?pid=S010264452009000200001\&script=sci_abstract\&tlng=pt. Acesso em: 06 ago. 2019.

FRASER, Nancy. Repensar el ámbito público: una contribución a la crítica de la democracia FRASER, Nancy. Unruly practices: power, discourse and gender in contemporary social theory. What's critical about Critical Theory? The case of Habermas and Gender. University of Minnesota Press: Minneapolis, 2013.

FRASER, Nancy; RAHEL Jaeggi. Capitalism: A conversation in critical theory. Cambridge: Polity Press, 2018.

\section{INSTITUTO DE PESQUISA ECONÔMICA APLICADA (IPEA). Retrato das desigualdades} de gênero e raça - 1995 a 2015. Brasília, 2015. Disponível em: http://www.ipea.gov.br/portal/images/stories/PDFs/170306_retrato_das_desigualdades_de_ge nero_raca.pdf. Acesso em: 06 ago. 2019.

MATOS, Marlise; PARADIS, Clarisse Goulart. Desafios à despatriarcalização do Estado brasileiro. Cadernos Pagu, Campinas, n. 43, p. 73, dez. 2014. Disponível em: http://www.scielo.br/pdf/cpa/n43/0104-8333-cpa-43-0057.pdf. Acesso em: 05 ago. 2019.

MELO, Hildete Pereira de. A política de cotas para as mulheres no Brasil: importância e desafios para avançar. In: Gênero e Número, São Paulo, 13 set. 2018. Disponível em: http://www.generonumero.media/a-politica-de-cotas-para-as-mulheres-no-brasil-importanciae-desafios-para-avancar/. Acesso em: 03 ago. 2019.

MIGUEL, Luís Felipe. Democracia e representação: territórios em disputa. 1. ed. São Paulo: Editora Unesp, 2014. 
MIGUEL, Luís Felipe. Teoria política feminista e liberal: o caso das cotas de representação. Revista Brasileira de Ciências Sociais, v. 15, n. 44, p. 91, out. 2000. Disponível: http://www.scielo.br/pdf/rbcsoc/v15n44/4149.pdf. Acesso em: 05 ago. 2019.

NÚMERO de mulheres eleitas em 2018 cresce 52,6\% em relação a 2014. In: TRIBUNAL Superior Eleitoral, Brasília, DF, 08 mar. 2019. Disponível em: http://www.tse.jus.br/imprensa/noticias-tse/2019/Marco/numero-de-mulheres-eleitas-em2018-cresce-52-6-em-relacao-a-2014. Acesso em: 31 jul. 2019.

PINHEIRO, Luana Simões et al. Mulheres e trabalho: breve análise do período 2004-2014. IPEA: Brasília, 2016.

PINTO, Céli Regina Jardim. A democracia desafiada: presença de direitos multiculturais. Revista USP, São Paulo, n. 42, p. 56-69, jul./ago. 1999. Disponível em: <https://doi.org/10.11606/issn.2316-9036.v0i42p56-69>. Acesso em: 13 maio 2019.

PINTO, Céli Regina Jardim. Redistribuir e reconhecer: aportes para a igualdade. In: MIGUEL, Luis Felipe; BIROLI, Flávia (Org.). Encruzilhadas da democracia.1. ed. Porto Alegre: Editora Zouk, 2014. p. 147-167.

QUAL É O SEU ODS?. In: PLATAFORMA AGENDA 2030. [S. l.]: Plataforma Agenda 2030, [2019?]. Disponível em: http://www.agenda2030.org.br/. Acesso em: 11 jul. 2019.

realmente existente. [S.1.], Metis Productos Culturales S.A. de C.V., 1993.

SILVA, Enrico Paternostro Bueno da. A teoria social crítica de Nancy Fraser: necessidade, feminismo e justiça, Brasil. 2013. 257 f. Dissertação (Mestrado em Sociologia) - Programa de Pós-Graduação em Sociologia do Instituto de Filosofia e Ciências Humanas da Universidade Estadual de Campinas (Unicamp), Campinas, 2013. Disponível em: $<$ http://www.bibliotecadigital.unicamp.br/document/?code=000919847>. Acesso em: 06 ago. 2019. 